\title{
Scoping out the literature on mobile needle and syringe programs-review of service delivery and client characteristics, operation, utilization, referrals, and impact
}

\author{
Carol Strike ${ }^{*}$ (D) and Miroslav Miskovic
}

\begin{abstract}
Background: Needle and syringe program (NSP) service delivery models encompass fixed sites, mobile services, vending machines, pharmacies, peer NSPs, street outreach, and inter-organizational agreements to add NSP services to other programs. For programs seeking to implement or improve mobile services, access to a synthesis of the evidence related to mobile services is beneficial, but lacking.

Methods: We used a scoping study method to search MEDLINE, PSYCHInfo, Embase, Scopus, and Sociological for relevant literature. We identified 39 relevant manuscripts published between 1975 and November 2017 after removing duplicates and non-relevant manuscripts from the 1313 identified by the search.

Results: Charting of the data showed that these publications reported findings related to the service delivery model characteristics, client characteristics, service utilization, specialized interventions offered on mobile NSPs, linking clients to other services, and impact on injection risk behaviors. Mobile NSPs are implemented in high-, medium-, and lowincome countries; provide equipment distribution and many other harm reduction services; face limitations to service complement, confidentiality, and duration of interactions imposed by physical space; adapt to changes in locations and types of drug use; attract people who engage in high-risk/intensity injection behavior and who are often not reached by other service models; and may lead to reduced injection-related risks.
\end{abstract}

Discussion: It is not clear from the literature reviewed, what are, or if there are, a "core and essential" complement of services that mobile NSPs should offer. Decisions about service complement for mobile NSPs need to be made in relation to the context and also other available services. Reports of client visits to mobile NSP provide a picture of the volume and frequency of utilization but are difficult to compare given varied measures and reference periods.

Conclusion: Mobile NSPs have an important role to play in improving HIV and HCV prevention efforts across the world. However, more work is needed to create clearer assessment metrics and to improve access to NSP services across the world.

Keywords: Needle and syringe programs, Mobile service, HIV prevention, Scoping study

\footnotetext{
* Correspondence: carol.strike@utoronto.ca

Dalla Lana School of Public Health, University of Toronto, Toronto, ON M5T3M7, Canada
} 


\section{Background}

A large body of evidence supports the effectiveness of needle and syringe programs (NSPs) to reduce injection risk behaviors that can lead to infections such as human immunodeficiency virus (HIV), hepatitis $\mathrm{C}(\mathrm{HCV})$, and other drug-related problems [1-5]. Over time, NSP service delivery models have expanded to encompass fixed sites, mobile services, vending machines, pharmacies, peer NSPs, street outreach, and inter-organizational agreements to add NSP services to other programs (e.g., hospitals, homeless shelters) [6-10]. The varied models of NSP service delivery are designed to improve access for people who use drugs in terms of time of day, geographic location, and service complement. In their guidelines, WHO, UNAIDS, and UNODC [11] recommend the use of mobile NSP units as an alternative and complementary source for delivery of NSP and other harm reduction services.

For programs seeking to implement or improve mobile services, access to a synthesis of the evidence related to mobile services is beneficial, but lacking. Systematic reviews of NSP-related evidence have been published but none provide an in-depth focus on the operational issues specific to mobile NSPs. Indeed, a review of reviews by Macarthur et al. found no reviews that examined the impact of mobile NSP on injection risk behaviors [3]. As programs attempt to break through the plateau reached in the prevention of injection-related blood-borne infections $[12,13]$ through service improvements, access to such a review can be helpful for decision-making and service design. We used a scoping study, a rigorous and comprehensive method [14], to identify and describe literature about mobile NSPs and specifically to answer this question: what is known about the design, operational characteristics, and services offered, client characteristics, service utilization, and impact of mobile NSPs? This method allowed for a broad charting of literature without narrow restrictions (e.g., specific populations, specific types of study designs, and/or highly specific definitions of methodological rigor) that might reduce what can be learned from existing literature $[14,15]$.

\section{Methods}

Using the methods put forth by Arksey and O'Malley [14], our scoping study was conducted in five stages: identify the research question, identify relevant studies, select the studies, chart the study data and collate, and summarize and report the results. The search strategy was designed to identify studies published before November 2017 that addressed any of the following: (1) the design, operational characteristics, and services offered, (2) client characteristics, (3) utilization, and (4) impact. We searched the following databases: MEDLINE, PSYCHInfo, Embase, Scopus, and Sociological abstracts using the following keywords:
- (needle* or syringe* or NSP or NEP or NEX) and (program* or exchange or outreach or distribution) and (mobile or van or bus);

- harm reduction and (program* or outreach or prevent $^{*}$ ) and (mobile or van or bus)

- harm reduction and (program* or outreach or prevent*) and (mobile or van or bus)

- harm reduction and (program* or outreach or prevent*) and (mobile or van or bus)

- (needle* $^{*}$ or syringe* or pipe* or NSP* or NEX or $\mathrm{NEP}^{*}$ ) and (crack or cocaine or meth or amphetamine or metamphetamine) and (HIV or $\mathrm{HCV}$ ) and (mobile or van or bus)

- (needle (n $^{*}$ or syringe ${ }^{*}$ or pipe ${ }^{*}$ or NSP* or NEX or $\mathrm{NEP}^{*}$ ) and (crack or cocaine or meth or amphetamine or metamphetamine) and (HIV or $\mathrm{HCV}$ ) and (mobile or van or bus).

Since our focus was on the mobile programs who offered the distribution of sterile injecting supplies as a main or a part of the services they offered, we excluded manuscripts about mobile programs that provided harm reduction services (e.g., substitution treatment, condom distribution, referrals, counseling, safer use leaflets, HAART treatment, $\mathrm{HIV} / \mathrm{HCV}$ testing) but did not offer NSP services. We also excluded manuscripts that reported the overall effectiveness of the NSP programs without specifically identifying a role of the mobile services, or lacked empirical data. We also excluded articles that pertained to mobile methadone maintenance treatment (MMT) or mobile-supervised injection sites unless they also provided needle and syringe distribution. Since we did not have resources to translate manuscripts, we excluded articles written in a language other than English. From this process, we identified 1313 manuscripts and after removing duplicates were left with 706 . We reviewed the full abstract for each manuscript and removed those that did not meet the eligibility criteria, which reduced the total number to 35 articles. Many manuscripts were excluded because empirical data were not reported. We identified another four relevant manuscripts from the reference lists of the included articles. Next, we searched Google Scholar using the same combination of keywords to find any additional manuscripts that were not captured using database searches. The Google search yielded 108 results of which eight met our inclusion criteria and had not been captured by previous searches.

Based on the extraction tool proposed by Arksley and O'Malley [14], we created an extraction tool specific to our scoping study to capture and organize data relevant to our research question. Data extracted from the studies were divided in five categories: (1) author/year, (2) study design, (3) methods and recruitment, (4) short description of the study/objectives, and (5) outcomes/findings. The 
extraction tool we used allowed us to "chart" the data-to identify what types of studies are available and what is the extent of the research on mobile NSPs and the main areas of interest. After the data were extracted and reviewed, three further articles were excluded from the study because the data presented were not relevant to our research question.

\section{Results}

Database and Google searches, as well as review of manuscript reference lists, yielded 43 relevant manuscripts with publication dates ranging from 1975 to November 2017 (see Table 1). Charting of the data showed that these publications reported findings related to the service delivery model characteristics, client characteristics, service utilization, specialized interventions offered on mobile NSPs, linking clients to other services, and impact on injection risk behaviors.

\section{Service delivery model characteristics}

From all the publications that met inclusion criteria, nine studies examined the service delivery characteristics and these originated from USA, Canada, and Russia. Mobile NSPs typically operate from vans and buses $[16,17]$. In addition to distribution and disposal of injection related equipment (e.g., needles/syringes, cookers, swabs, and/or biohazard bins), reports show that some mobile NSPs offer harm reduction education, HIV testing and counselling, urine screening for sexually transmitted infections, distribution of equipment to smoke drugs (e.g., crack kits), emergency medical help, peer counseling, condom distribution, drug treatment information and referrals, referrals to other services (e.g., reproductive health), methadone maintenance treatment, and supervised injection services [18-25].

Space was noted to limit the total number of services that can be offered on board and also create impediments to client privacy when they access mobile NSP services [26]. A study in 2010 by MacNeil and Pauly examined the changes in services after a mobile NSP was introduced following the forced closure of a fixed site NSP [27]. The mobile NSP was reported to have maintained contact with the clients and provided basic services but was insufficient to compensate for the full range of service previously offered by the fixed site. Contacts with clients through mobile NSP were of shorter duration and mainly reduced to providing new needles. For that reason, most clients advocated for operation of both fixed and mobile site NSP [27].

Mobile NSPs are designed to serve clients in varied locations and often at times when NSP services may not be available. Mobile outreach units can cover a large geographic area, often follow predictable routes, and make stops at prearranged times when clients are most likely to access services. In Volgograd, Russia, a mobile van covered three networks of drug users during the 40-km stretch along the Volga River in addition to a fixed-site NSP [28]. As well as stopping at public locations, some mobile NSPs respond to client telephone requests for delivery of equipment to their homes and through secondary peer distribution [26]. Strike and colleagues (2002) note that through home delivery mobile NSPs in Ontario, Canada, were able to serve clients with disabilities and those who did not want to access fixed-site NSP [26].

Studies report that mobile NSPs can adapt service delivery to changes in local drug scene and incorporate additional populations of people who use drugs better than do other models of NSP service delivery $[8,17,29]$. A study from Vancouver showed [30] that when cocaine became the predominant drug used for injecting, demand for needles increased and the number of mobile NSPs was increased from one to three to meet the rising demand for injecting equipment.

In locations with high police surveillance, mobile NSPs can make accessing services less identifying for clients [17]. Tinsman et al. [31] examined 12 outreach projects in the USA and found that mobile NSP projects were highly recognized by the local community of people who use drugs, provided a safer and relatively private environment for interaction between clients and staff to receive harm reduction services and HIV testing. Conversely, mobile NSPs were noted to be less recognizable and to attract less attention from neighbors, local businesses, and the police [17]. Somlai et al. [32] reported that mobile NSPs are more acceptable to community residents who fear that a fixed site will draw violent and criminal behavior to the neighborhood.

Although mobile NSPs can visit several locations a day, reports note that services are often provided for limited amounts of time and may be a barrier to accessing clean needles [27, 29, 30,33]. Some people who use drugs might not be able to access services during those times and may not be covered by through mobile outreach [29]. Hyshka et al. [30] found that the mobile van was the only outlet providing needles during evening hours in Vancouver and many people who use drugs were not covered either by the fixed-site or mobile program. Wood and colleagues [33] suggested that "missing the van" could be considered as a risk factor for high-risk needle sharing since needle sharing was 3.5 times higher in the population of users who had difficulty accessing new needles through the van compared to those who did not have difficulty.

\section{Client characteristics}

A total of 14 studies examined the characteristics of the clients who accessed mobile NSP services. These studies originated from the USA (including Puerto Rico), Ireland, Canada, France, Nigeria, and Germany. While the design, objectives, and measured outcomes varied, 


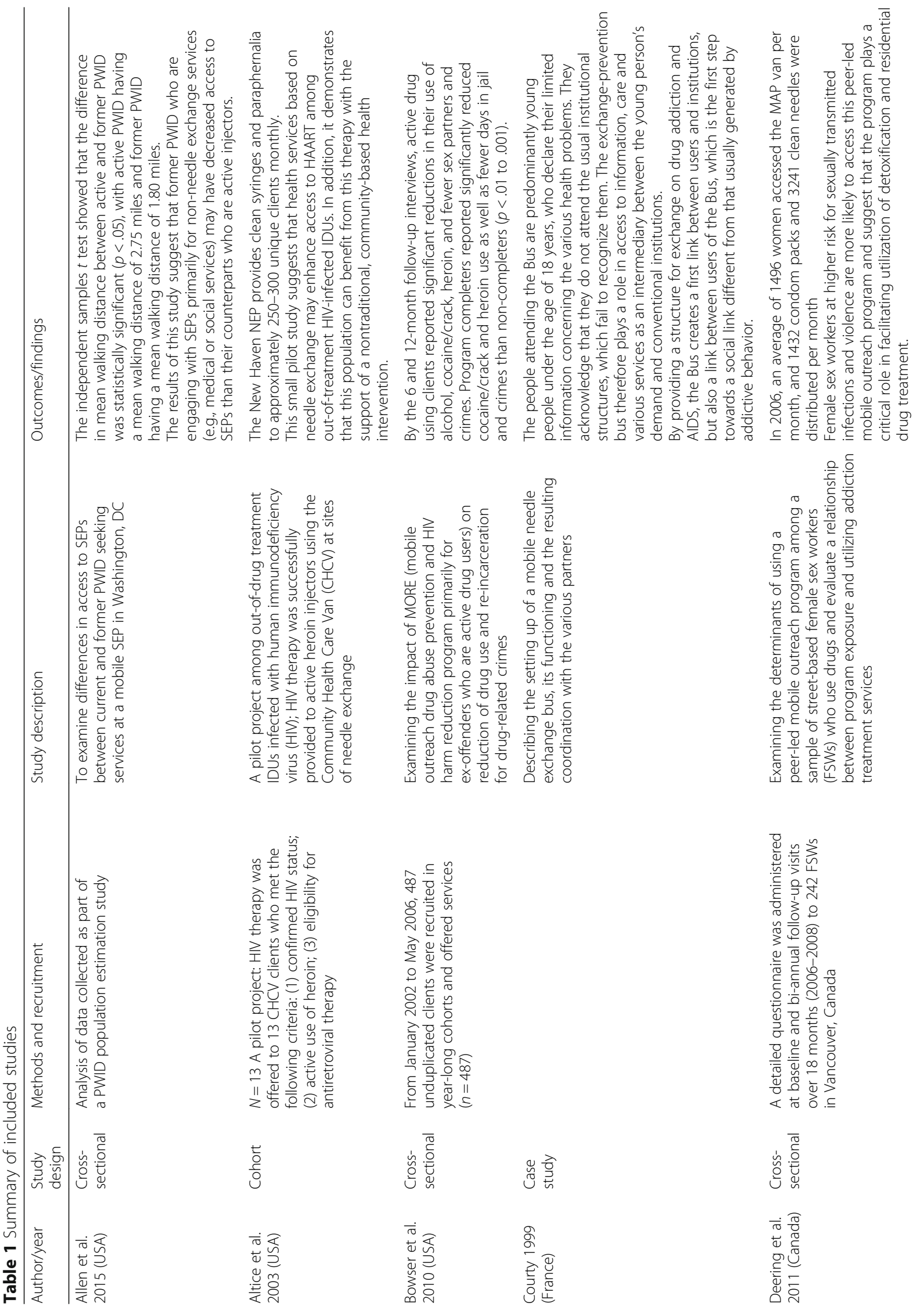




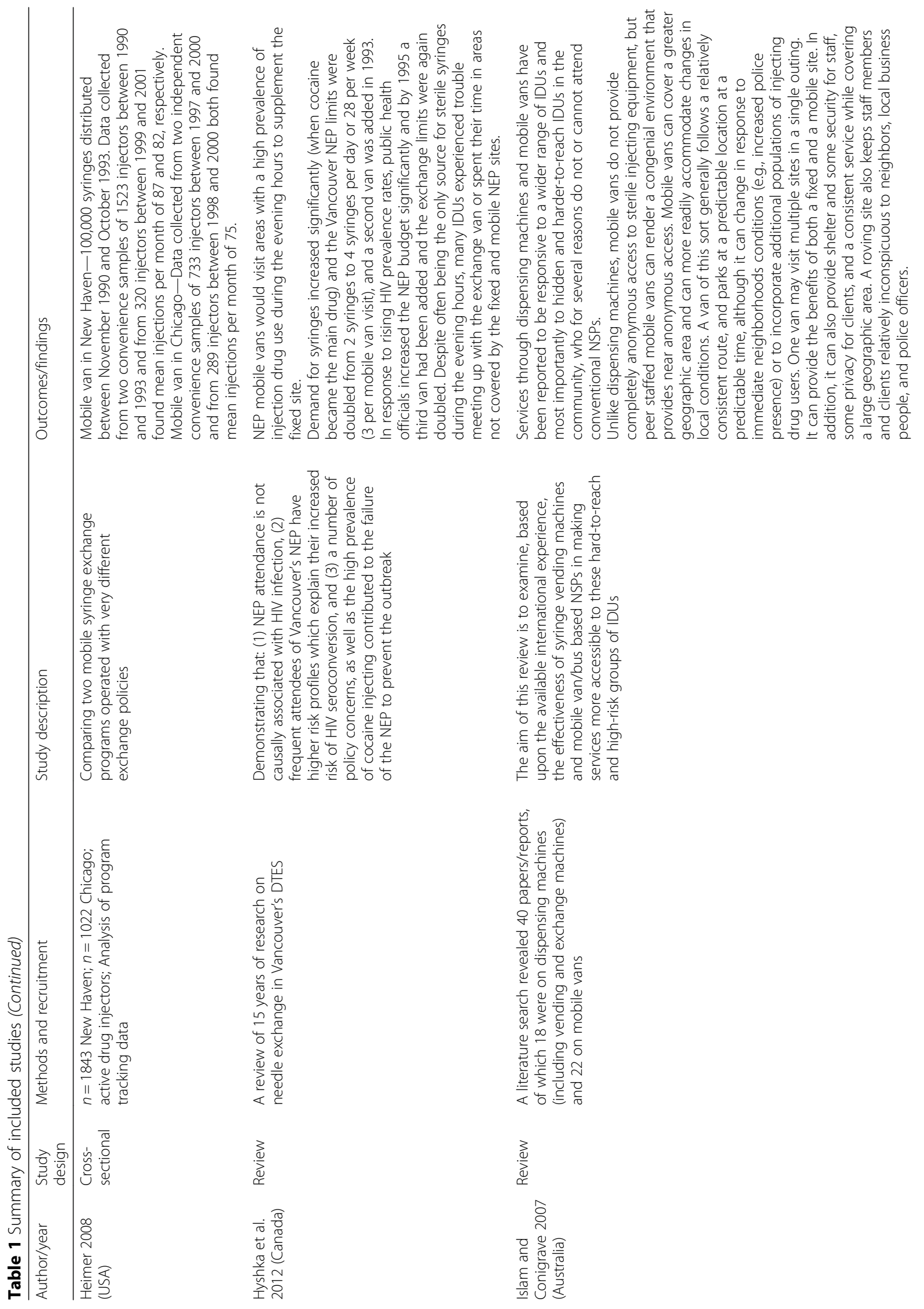




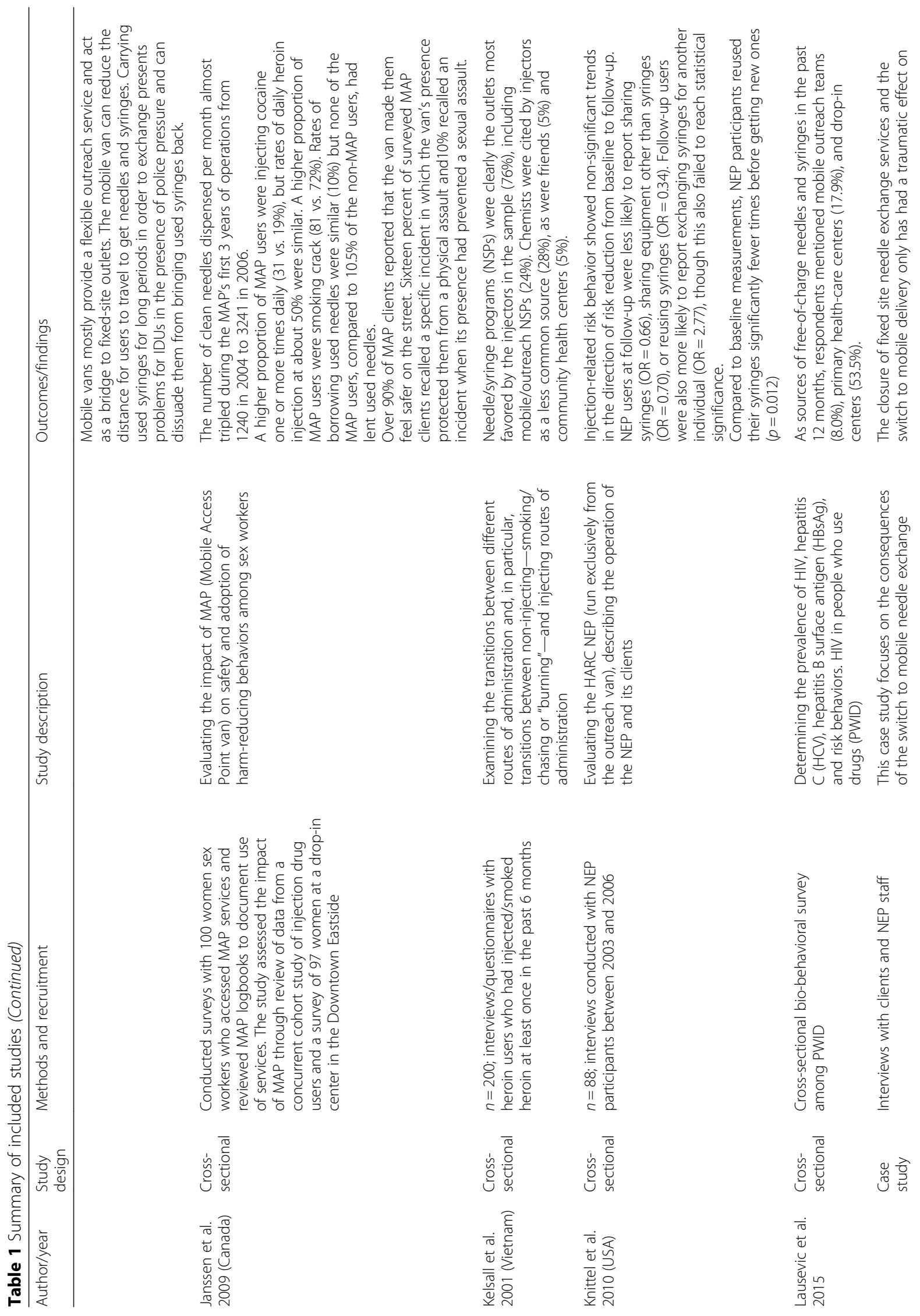


Strike and Miskovic Harm Reduction Journal (2018) 15:6

Page 7 of 15

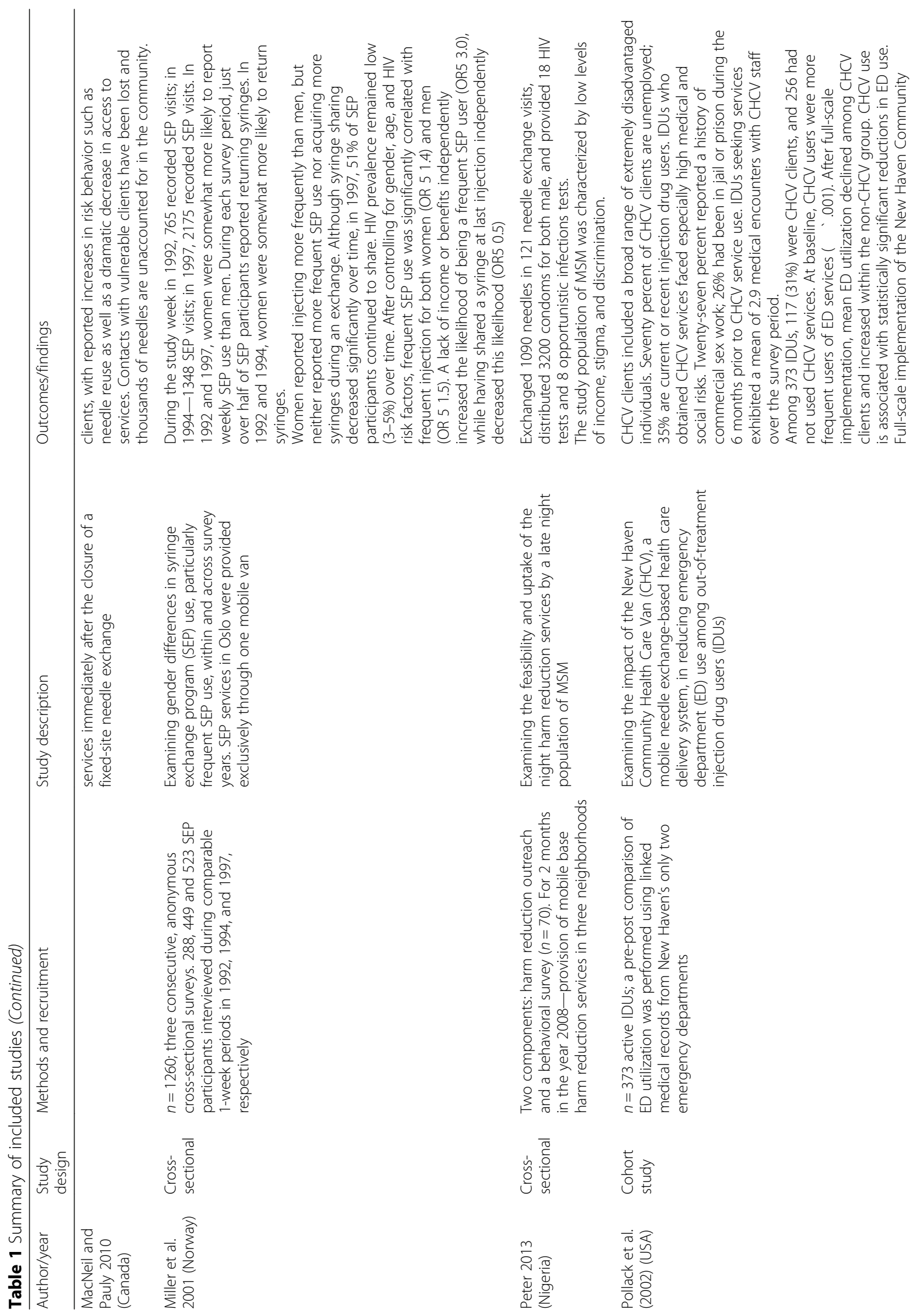




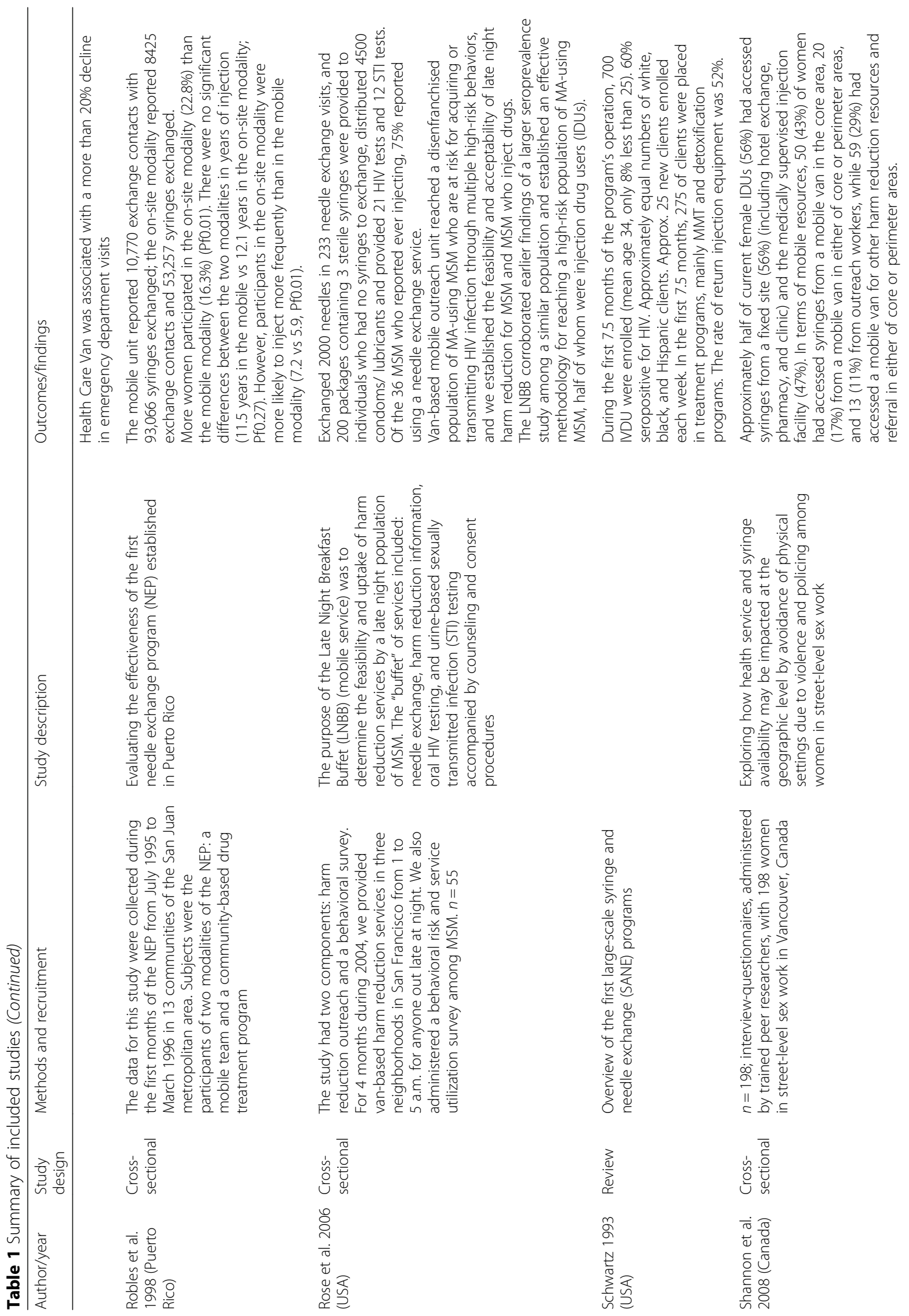




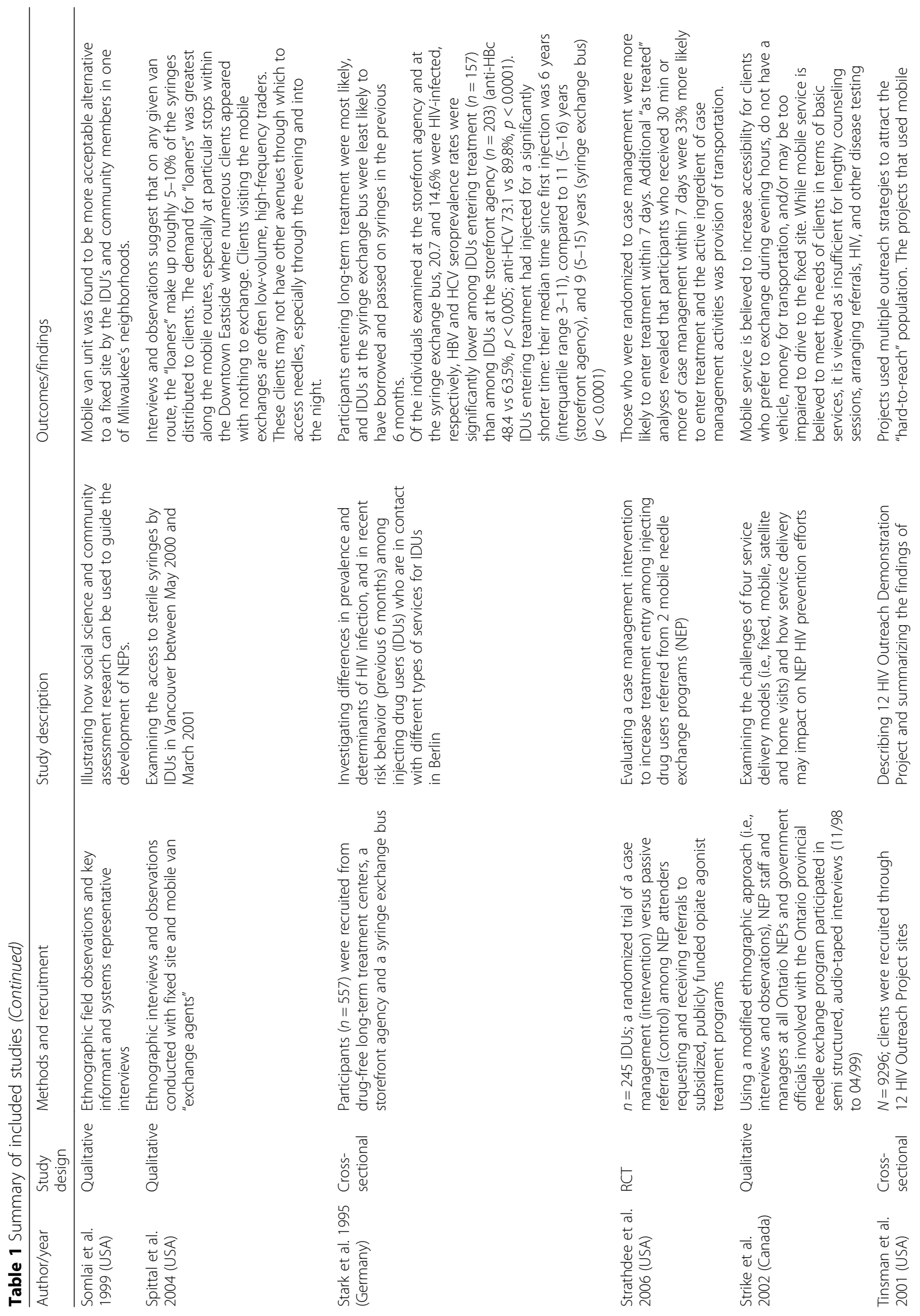




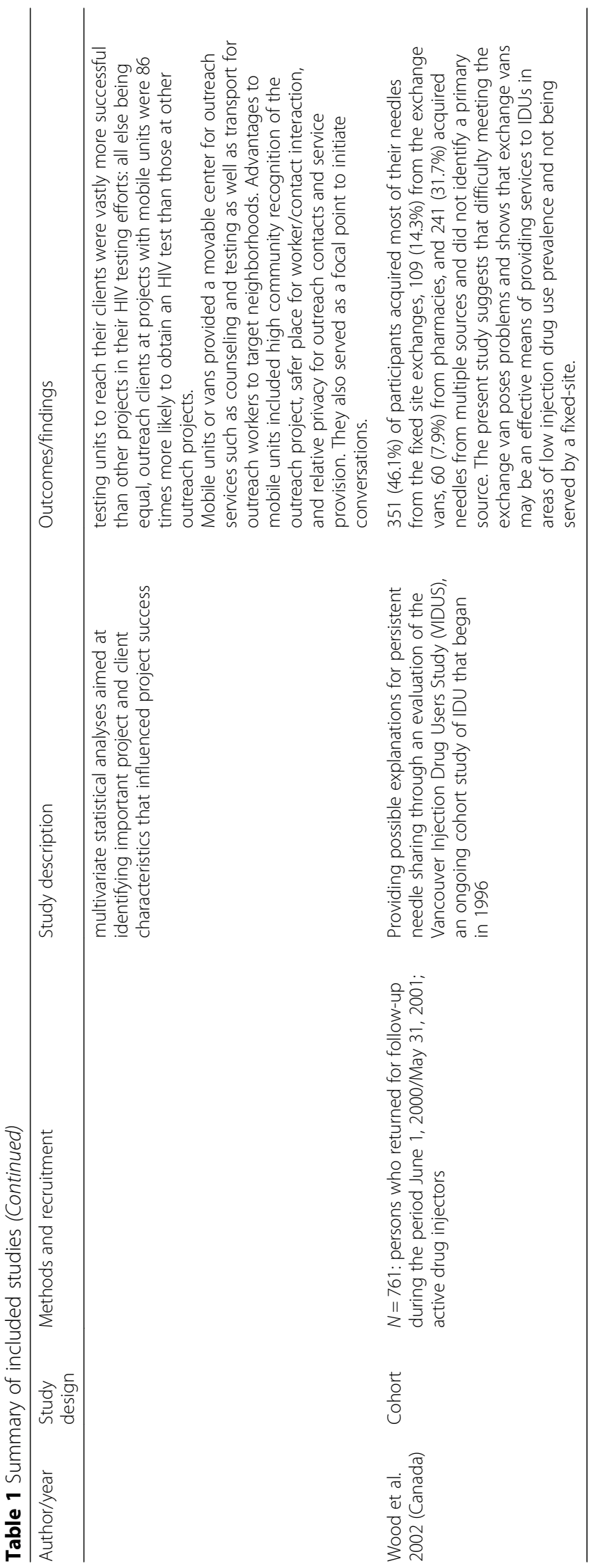


all 14 studies confirmed that mobile NSP units attract people who use drugs and report high-risk injection behaviors [5, 6, 8, 17-20, 34-39] and also populations not covered by other service models [17-21, 33, 39-48]. Mobile NSPs were noted to increase access for "hard-to-reach populations" by removing the barriers such as fear of public exposure occasioned by entering a fixed site, stigma, mobility issues associated with physical disability, local policing practices that discourage attendance at fixed sites, and poor availability of public transportation services [49].

Specifically, mobile NSPs were shown to attract people who are under the age of 18 [41], homeless [17], out-ofdrug-treatment [42], men who have sex with men and who use methamphetamines [19, 20], women involved in street-level sex work [18, 22, 39, 43], drug-using exoffenders [21], and the Roma population [44]. In San Francisco [19] and Nigeria [20], the mobile NSPs were designed to reach men who have sex with men and who inject drugs. Courty [41] reported that clients attending mobile NSP bus at Clermont Ferrand, France, were predominantly younger (under the age of 18), had limited information regarding various health issues, and were not in contact with other health and service providers.

Studies show mixed results in terms of the gender of the clients reached by mobile NSPs. Allen et al. [50] reported that the majority of participants (71\%) accessing the largest mobile NSP in Washington, USA, were male. Conversely, a study from Vancouver reported that the mobile NSP served a higher percentage of female clients [17]. A study from Puerto Rico found that clients who accessed mobile NSP were less likely to be female compared to a fixed site [35]. In Oslo, Miller et al. [51] found that in 1992 and 1997, women were somewhat more likely than men to report weekly use of the mobile NSP in Oslo, Norway.

Studies also show that mobile NSPs tend to attract high frequency and higher risk injectors than fixed site or pharmacy-based programs $[6,8]$. Several studies reported that the frequency of injection was high among the clients accessing mobile NSP [5, 8, 17, 19, 29, 37, 38, 52]. In Oslo, Norway, clients used more needles each day than clients attending other service models [29]. In other studies, results show mobile NSPs attracted populations of highrisk cocaine injectors $[8,18,39]$. Conversely, a study in Puerto Rico, by Robles et al. [35] found that clients of the fixed sites reported a higher frequency of injecting than clients who used the mobile service.

Riley et al. found that clients accessing van-based outreach services in Baltimore were more likely to be cocaine injectors, to have injected with previously used needles, and inject more frequently than clients who accessed services at pharmacies [8]. In Vancouver, sex workers who accessed van-based services provided by the Mobile Access Point were found to be more likely to have injected cocaine one or more times daily in the last 6 months than sex workers who were clients of the drop-in center at the Downtown Eastside, Vancouver [18]. Rose et al. [19] found that high rates of methamphetamine use among clients accessing mobile van providing harm reduction services including NSP to the late night population of men who have sex with men (MSM) in San Francisco. Of all MSM clients, the majority of MSM (97\%) injected methamphetamine and 13\% injected it several times a day. Methamphetamine use and alcohol consumption were noted as risk factors for having unprotected sex among HIV-negative and HIV-positive MSM [19].

Needle sharing, borrowing, and re-use were found to be higher among the population of clients reached by mobile NSPs [8, 53]. However, a study conducted in Berlin showed that clients of the mobile NSP were less likely to have shared and borrowed needles in the last 6 months than clients using other service models [34].

Two studies reported that the mobile NSP served sex workers who tended to have more clients on average in the last week, to provide sex services to clients in alleys, industrial sites, and an outdoor setting, compared to clients who did not use mobile NSP services [18, 39]. A study from 2008 [43], showed that although the majority of female sex workers who use drugs (56\%) obtained needles from a fixed site, a mobile NSP unit was an important venue for accessing needles and other harm reduction services in several different locations in Vancouver. Specifically, $43 \%$ of women had accessed needles from a mobile NSP in the core area, $17 \%$ from a mobile NSP in either of core or perimeter areas, and $11 \%$ from outreach workers, while $29 \%$ had accessed a mobile NSP for other harm reduction resources and referral in either of core or perimeter areas. From a survey of 100 women in a drop-in center in Downtown Eastside in Vancouver, Janssen et al. [18] reported that $81 \%$ of women had accessed services in the Mobile Access Point (MAP), a peer-led mobile NSP unit that provided emergency medical help, peer counseling, condoms, and new needles, resource information, and referral. The majority of women (44.8\%) reported accessing MAP services once each night, and the remainder of women accessed services twice each night (20.9\%), twice weekly $(17.9 \%)$, once weekly $(11.9 \%)$, or less frequently (3.0\%) [18]. In 2006, an average of 1496 women accessed the MAP van per month [39].

\section{Service utilization data}

A total of 10 studies reported service utilization data and these originated from the USA, Canada, Nigeria, Germany, Norway, Lithuania, and Montenegro. The New Haven Needle Exchange mobile van reached 700 
clients in the first 7 months of operation. Of these, $60 \%$ were seropositive for HIV [54]. In San Francisco [19], a mobile unit exchanged 2000 needles in 233 exchange visits over a 4-month period in 2004. A study assessing the percentage of the at-risk population reached by mobile NSP in two US cities, New Haven and Chicago [38], found that 100,000 needles were distributed between November 1990 and October 1993 by a mobile NSP in New Haven. In 2004, a mobile NSP in Chicago reached an average of 1000 clients every month [38]. Janssen et al. reported that the number of needles dispensed through the Vancouver Mobile Access Project tripled during the first 3 years of its operation, from 1240 in 2004 to 3241 in 2006. An average of 1496 clients per month accessed MAP van in 2006 [18]. In Nigeria, a mobile NSP project exchanged 1090 needles across 121 visits between July and September 2007 [20]. The only existing NSP program in Oslo [51], which operated from a mobile van showed that the number of visits tripled between 1992 and 1997 (i.e., 765 visits in 1992, 1348 in 1994, and 2175 in 1997). The "Blue Bus" exchange project started in 2001 in Vilnius, Lithuania, and it recorded high numbers of distributed needles in the first months of operation [44]. An already existing outreach program that operated without a mobile unit in Vilnius distributed 16,700 needles and 17,350 needles in the first year of its operation (1997), and with the addition of a mobile NSP, the number of distributed equipment increased significantly: 56,000 syringes and 64,580 needles distributed in 2001, and 73,408 syringes and 87,733 needles in 2002. Within 1 month from the beginning of the operations of the "Blue Bus," 350 clients were using its services. The "Blue Bus" project in Vilnius was able to reach $40 \%$ of the city's population of people who inject drugs. Fischer [55] stated that mobile NSP programs in Frankfurt were the major source for needle distribution, providing $80 \%$ of all needles in the city.

In Podgorica, Montenegro, 8\% of clients reported using a mobile NSP to access new needles in the last 12 months but many more reported accessing these supplies at primary health-care centers (17.9\%) and drop-in centers (53.5\%) [56]. In Vietnam, Kelsall et al. [57] found that $76 \%$ of clients reported using NSP as a preferred outlet for accessing needles, including mobile/ outreach NSPs (24\%).

Some mobile NSPs also collect used equipment for disposal [51, 54]. Indeed, in New Haven, Connecticut, Schwartz reported that $52 \%$ of used injecting equipment was collected by the mobile van [54]. In Oslo, Norway, rate of returned needles was over $50 \%$ during the three survey periods of the study-1992, 1994, and 1997-and women were found to be more likely to return needles for the first two survey periods [51].

\section{Referral of clients to other services}

We identified eight studies from the USA, Canada, Germany, and France, which reported on efforts to refer clients to services which were not available directly through mobile NSP [5, 31, 39, 41, 42, 54]. Schwartz [54] found that within 7.5 months of operation, 275 clients of the mobile NSP in New Haven, Connecticut, were admitted to drug treatment programs (i.e., most methadone maintenance) through referrals offer by van staff. The bus operating in Clermont Ferrand, France, referred young people who injected drugs to health and social services that previously had not been accessed [41]. The CHCV van in Baltimore found that $64 \%$ of the clients who received HAART treatment through a mobile NSP also were successfully referred to and entered into drug treatment in the 12-month follow-up period [42]. In Vancouver, a mobile NSP that served a high-risk population of sex workers was found to have an important role in facilitating entry and increasing utilization of residential and detoxification treatment. During the 18-month period of the study, accessing inpatient addiction treatment was reported 45 times and outpatient treatment was reported 162 times. Accessing the mobile NSP was significantly associated with the utilization of inpatient addiction treatment [39]. Similarly, a project in Ypsilanti, Michigan [53], where NSP was provided through a HIV/AIDS Resource Center (HARC) Harm Reduction mobile van, showed between 2003 and 2006 the clients in the follow-up period (6 months after they started using van services) were more likely to enter drug treatment compared to the baseline group.

\section{Specialized interventions}

A total of three studies conducted in USA and Canada explored the impact of specialized interventions delivered through mobile NSPs. Pollack et al. [36] found that the Community Health Care Van (CHCV) in New Haven, a mobile-based NSP and health care delivery system, was effective in reducing the rates of emergency department use among out-of-treatment injection drug users. The van, equipped with two examination and one counselling room, provided clinical care, diagnosis, and treatment of tuberculosis and syphilis vaccination and general health education. Even though $35 \%$ of the clients who used $\mathrm{CHCV}$ services faced high medical and social risk, full-scale implementation of the $\mathrm{CHCV}$ van services resulted in a more than 20\% decline in emergency department visits. Altice and colleagues [42] reported on a pilot project offering HIV treatment and also HIV counseling, case management, drug treatment coordination, health status assessment, and acute and episodic medical care on a mobile NSP. This pilot project involved the delivery of HAART treatment through the $\mathrm{CHCV}$ van 
to active heroin injectors at the mobile NSP locations. Through this pilot project, 13 clients initiated antiretroviral therapy in the mobile NSP and of these, 9 (69\%) entered drug treatment once they achieved non-detectable viral load. The authors suggested that the delivery of HAART therapy through mobile NSP can improve access to HAART treatment for the population of out-of-treatment HIV-positive drug users who are already using mobile NSP services.

A randomized control trial in Baltimore [58], showed that provision of case management through a mobile NSP was successful to facilitate referrals for entry into drug treatment. The authors reported that NSP clients who were randomized to case management were more likely to enter drug treatment within 7 days than the clients who received only a passive referral to treatment. The case management group also received transportation to treatment settings suggesting that offering transportation may reduce barriers to treatment for disadvantaged populations of people who use drugs [58].

\section{Impact of mobile NSPs on injection risk behaviors}

Only two studies reported the impact of mobile NSP on rates of needle sharing. A study in Oslo found a significant decrease in past year needle sharing from $64 \%$ of clients in 1992 to $51 \%$ in 1997 [51]. In a study by Knittel et al. [53], NSP staff in Ypsilanti, Michigan, interviewed clients at intake and after 6 months of accessing the HARC NEP that operated 3 days a week from a van. After 6 months of using HARC mobile NEP services, clients were less likely to share needles $(\mathrm{OR}=0.66)$, share injecting equipment other than needles $(\mathrm{OR}=0.34)$, and reuse needles $(\mathrm{OR}=0.34)$ compared to baseline reports. Although the study collected data at only one point in time, Subata and Kriksciukaityte [44] noted that $96 \%$ of clients did not re-use needles and $88 \%$ did not share needles in the last 30 days and attributed these rates to use of the mobile NSP in Vilnius.

\section{Discussion}

Riley et al. recommend implementation of several NSP service delivery models to offset the limitations of particular models and improve access for clients [8]. In terms of contribution to NSP goals, results from this scoping study show that mobile NSPs:

- Have been implemented across the world in high-, medium-, and low-income countries

- In addition to distributing injection-related equipment, provide a wide range of other harm reduction, health, and social services

- Face limitations to service complement, confidentiality, and duration of interactions imposed by physical space
- May shield program utilization from police observation

- Can adapt to changes in locations and types of drug use

- Attract people who engage in high-risk and highintensity injection behaviors

- Attract clients with diverse social characteristics and who are often not reached by other service models

- Provide referrals to varied health and addiction services

- Can offer specialized interventions onboard (e.g., primary care, HIV treatment, case management)

- May lead to reduced injection-related risks

It is not clear from the literature reviewed, however, what are, or if there are, a "core and essential" complement of services that mobile NSPs should offer. Decisions about service complement for mobile NSPs need to be made in relation to the context and also other available services. The WHO, UNODC, UNAIDS technical guide [11] provide guidance regarding essential HIV prevention services and in addition to NSP services includes on the list services that some mobile NSPs do offer (i.e., opioid substitution therapy; HIV testing and counselling; antiretroviral therapy; prevention and treatment of sexually transmitted infections; condom distribution; targeted information, education and communication and prevention, vaccination, diagnosis and treatment for viral hepatitis). As well, the WHO recommends a variety of ways to make services user friendly that are directly addressed by mobile NSPs (e.g., co-location of interventions, strategic location of services in "hotspots") [11].

Reports of client visits to mobile NSP provide a picture of the volume and frequency of utilization but are difficult to compare given varied measures and reference periods. Measures of program coverage and reach [59] might provide clearer metrics to assess mobile NSPs as standalone interventions, as part of an NSP offering varied services models and in relation to larger HIV prevention activities. However it is important to highlight that although member states at the UN General Assembly Special Session on Drugs endorsed NSPs as one of several programs to reduce adverse public health consequences of drug abuse, a recent report from Harm Reduction International noted that NSP coverage across the world is below the level required to prevent HIV and HCV among people who inject drugs.

Our scoping study is not without its limitations. First, we searched the published, English literature for studies reporting empirical literature about mobile NSPs. As such, non-English and grey literature is not included in our summary of the extant literature and may not reflect all that is known across the globe about mobile NSPs. 
However, given time and budget constraints, we did not search the grey literature which is vast and with potential reports embedded and repeated within and across many websites. In addition, if there had been resources for a search of the grey literature, we would have had to assess but may not have had sufficient information to determine if the methods used to collect the data supported the findings reported. Second, this scoping study includes and disseminates findings from a range of studies utilizing different methods and study designs providing narrative or descriptive accounts of available empirical research but does not provide a quality appraisal needed for a systematic review. This is typical for scoping studies. Given the heterogeneity of the study designs and data collected reported in this manuscript, we did not proceed with a systematic review. Third, the two authors met and agreed on the search strategy, inclusion, and exclusion criteria; reviewed each abstract; and reached consensus on the organization, extraction, and charting of the data. It could be that others may organize the data differently, but we believe our presentation of the findings is faithful to the original studies.

\section{Conclusion}

Mobile NSPs have an important role to play in improving HIV and $\mathrm{HCV}$ prevention efforts across the world. However, more work is needed to create clearer assessment metrics and to improve access to NSP services across the world.

\section{Abbreviations \\ HCV: Hepatitis C; HIV: Human immunodeficiency virus; NSP: Needle and syringe programs}

\section{Acknowledgements \\ We are deeply grateful to the following staff and team members who contributed their time and expertise to the best practices project: Tara Marie Watson, Ashraf Amlani, Camille Arkell, Jane Buxton, Hemant Gohil, Natalia Gutiérrez, Shaun Hopkins, Hugh Lampkin, Jenny Lebounga Vouma, Pamela Leece, Lynne Leonard, Lisa Lockie, Peggy Millson, Carole Morissette, Diane Nielsen, Darren Petersen, Samantha Robinson, Despina Tzemis, and Sara Young. The project would not have been possible without their invaluable insights.}

\section{Funding}

This study was funded by the Canadian Institutes of Health Research CBR127101.

\section{Availability of data and materials}

Not applicable

\section{Authors' contributions}

CS and MM both designed and completed this scoping study, wrote and edited the manuscript, gave final approval for it to be published, and agree to be accountable for its content.

Ethics approval and consent to participate

Not applicable

\section{Consent for publication}

Not applicable

\section{Competing interests}

The authors declare that they have no competing interests.

\section{Publisher's Note}

Springer Nature remains neutral with regard to jurisdictional claims in published maps and institutional affiliations.

Received: 14 November 2017 Accepted: 31 January 2018

Published online: 08 February 2018

\section{References}

1. Aspinall EJ, Nambiar D, Goldberg DJ, Hickman M, Weir A, Van Velzen E, Palmateer N, Doyle JS, Hellard ME, Hutchinson SJ. Are needle and syringe programmes associated with a reduction in HIV transmission among people who inject drugs: a systematic review and meta-analysis. Int J Epidemiol. 2014;43(1):235-48.

2. Abdul-Quader AS, Feelemyer J, Modi S, Stein ES, Briceno A, Semaan S, Des Jarlais DC. Effectiveness of structural-level needle/syringe programs to reduce HCV and HIV infection among people who inject drugs: a systematic review. AIDS Behav. 2013:17(9):2878-92.

3. MacArthur GJ, van Velzen E, Palmateer N, Kimber J, Pharris A, Hope V, et al. Interventions to prevent HIV and Hepatitis $C$ in people who inject drugs: a review of reviews to assess evidence of effectiveness. Int J Drug Policy. 2014;25(1):34-52.

4. Palmateer N, Kimber J, Hickman M, Hutchinson S, Rhodes T, Goldberg D. Evidence for the effectiveness of sterile injecting equipment provision in preventing hepatitis $C$ and human immunodeficiency virus transmission among injecting drug users: a review of reviews. Addiction. 2010;105:84459.

5. Jones $L$, Pickering $L$, Sumnall $H$, McVeigh J, Bellis MA. Optimal provision of needle and syringe programmes for injecting drug users: a systematic review. Int J Drug Policy. 2010;21:335-42.

6. Miller CL, Tyndall M, Spittal P, Li K, Palepu A, Schechter Tyndallo: Risk-taking behaviors among injecting drug users who obtain syringes from pharmacies, fixed sites and mobile van needle exchanges. J Urban Health. 2002;79 (2): 257-265

7. Obadia Y, Feroni I, Perrin V, Vlahov D, Moatti JP. Syringe vending machines for injection drug users: an experiment in Marseille, France. Am J Public Health. 1999;89(12):1852-4.

8. Riley ED, Safaeian M, Strathdee SA, Marx MA, Huettner S, Beilenson P, Vlahov D. Comparing new participants of a mobile versus a pharmacybased needle exchange program. J Acq Immun Def Synd. 2000;24(1):57-61.

9. Bryant J, Treloar C. Risk practices and other characteristics of injecting drug users who obtain injecting equipment from pharmacies and personal networks. Int J Drug Policy. 2006;17(5):418-24.

10. Bryant J, Topp L, Hopwood M, Iversen J, Treloar C, Maher L. Is point of access to needles and syringes related to needle sharing? Comparing data collected form pharmacies and needle and syringe programs in South-East Sydney. Drug Alcohol Rev. 2010;29(4):364-70.

11. WHO, UNODC. UNAIDS technical guide for countries to set targets for universal access to HIV prevention, treatment and care for injecting drug users. Geneva: World Health Organization, United Nations Office on Drugs and Crime, Joint United Nations Programme on HIV/AIDS; 2009.

12. Coquhoun R, Christian G. HIV and HCV transmission among intravenous drug users. J Global Drug Policy Prac. 2004;8(3):1-39.

13. Martin RE, Gold F, Murphy W, Remple V, Berkowitz J, Money D. Drug use and risk of bloodborne infections: a survey of female prisoners in British Columbia. Can J Public Health. 2005;96(2):97-101.

14. Arksey H, O'Malley L. Scoping studies: towards a methodological framework. Int J Soc Res Methodol. 2005;8:19-32.

15. Broyles LM, Conley JW, Harding JD Jr, Gordon AJ. A scoping review of interdisciplinary collaboration in addictions education and training. J Addict Nurs. 2013:24(1):29-36.

16. Rhodes T, Stimson GV, Crofts N, Ball A, Dehne K, Khodakevich L. Drug injecting, rapid HIV spread, and the 'risk environment': implications for assessment and response. AIDS. 1999;13(Supp A):259-69.

17. Islam MM, Conigrave KM. Assessing the role of syringe dispensing machines and mobile van outlets in reaching hard-to-reach and high-risk groups of injecting drug users (IDUs): a review. Harm Reduct J. 2007a;4:14.

18. Janssen PA, Gibson K, Bowen R, Spittal PM, Peterson KL. Peer support using a mobile access van promotes safety and harm reduction strategies among 
sex trade workers in Vancouver's Downtown Eastside. J Urban Health. 2009; 86(5):804-9.

19. Rose VJ, Raymond HF, Kellogg TA, McFarland W. Assessing the feasibility of harm reduction services for MSM: the late night breakfast buffet study. Harm Reduct J. 2006;3:29. -10.1186/1477-7517-3-29

20. Peter ODO. Night harm reduction services accessibility for prevention: a model of success. Sex Transm Infect. 2013;89(Suppl 1):A321.

21. Bowser BP, Jenkins-Barnes T, Dillard-Smith C, Lockett G. Harm reduction for drug abusing ex-offenders: outcome of the California prevention and education project MORE project. J Evid Based Soc Work. 2010;7(1):15-29.

22. Moore E, Han J, Serio-Chapman C, Mobley C, Watson C, Terplan M. Contraception and clean needles: feasibility of combining mobile reproductive health and needle exchange services for female exotic dancers. Am J Public Health. 2012;102(10):1833-6.

23. Buning EC, Van Brussel GH, Van Santen G. The "methadone by bus" project in Amsterdam. Br J Addict. 1990;85:1247-50.

24. Lowinson JH, Ruiz P, Millman RD, et al., editors. Substance abuse: a comprehensive textbook. 3rd ed. Baltimore, MD: Williams \& Wilkins; 1997.

25. Dietze P, Winter R, Pedrana A, Leicht A, Majo I, Roca X, Brugal MT. Mobile safe injecting facilities in Barcelona and Berlin. Int J Drug Policy. 2012;23(4): 257-60.

26. Strike CJ, Challacombe L, Myers T, Millson M. Needle exchange programs: delivery and access issues. Can J Public Health. 2002;93(5):339-43.

27. MacNeil J, Pauly B. Impact: a case study examining the closure of a large urban fixed site needle exchange in Canada. Harm Reduct J. 2010;7:11.

28. Klaassen R. Syringe exchange by automat. Int J Drug Policy. 1989;1(3):6-7.

29. Miller CL, Tyndall MW, Li K, Spittal PM, Schechter MT. Needle exchange source and risk taking behaviors among injection drug users. Can J Infect Dis. 2001;12:70B.

30. Hyshka E, Strathdee SA, Wood E, Kerr T. Needle exchange and the HIV epidemic in Vancouver: lessons learned from 15 years of research. Intl J Drug Policy. 2012;23(4):260-70.

31. Tinsman PD, Bullman S, Chen X, Burgdorf $K$, Herrell JM. Factors affecting client response to HIV outcome efforts. J Subst Abus. 2001;13:201-14.

32. Somlai AM, Kelly JA, Otto-Salaj L, Nelson D. "Lifepoint": a case study in using social science community identification data to guide the implementation of a needle exchange program. AIDS Educ Prev. 1999;11(3):187-202.

33. Wood E, Tyndall M, Spittal P, Li K, Kerr T, Hogg R, O'Shaughnessy M, Schechter M. Needle exchange and difficulty with needle access during an ongoing HIV epidemic. Int J Drug Policy. 2002;13(2):95-102.

34. Stark K, Müller R, Wirth D, Bienzle U, Pauli G, Guggenmoos-Holzmann I. Determinants of HIV infection and recent risk behavior among injecting drug users in Berlin by site of recruitment. Addiction. 1995;90:1367-75.

35. Robles RR, Colón HM, Matos TD, Finlinson HA, Muñoz A, Marrero CA, García M, Reyes JC. Syringe and needle exchange as HIV/AIDS prevention for injection drug users in Puerto Rico. Health Policy. 1998:45(3):209-20.

36. Pollack H, Khoshnood K, Blankenship K, Altice F. The impact of needle exchange-based health services on emergency department use. J Gen Intern Med. 2002:17(5):341-8.

37. Spittal PM, Small W, Wood E, et al. How otherwise dedicated AIDS prevention workers come to support state-sponsored shortage of clean syringes in Vancouver, Canada. Int J Drug Policy. 2004;15:36-45.

38. Heimer R. Community coverage and HIV prevention: assessing metrics for estimating HIV incidence through syringe exchange. Int J Drug Policy. 2008; 19(S1):S65-73.

39. Deering KN, Kerr T, Tyndall MW, Montaner JS, Gibson K, Irons L, Shannon K. A peer-led mobile outreach program and increased utilization of detoxification and residential drug treatment among female sex workers who use drugs in a Canadian setting. Drug Alcohol Depen. 2011;113(1):4654.

40. Bardsley J, Turvey J, Blatherwick J. Vancouver's needle exchange program. Can J Public Health. 1990;81:39-45.

41. Courty P. Setting up of a health care network for drug addicts. An original strategy of access to care: the exchange-prevention bus. Annales de Psychiatrie. 1999;14(3):214-9.

42. Altice FL, Springer S, Buitrago M, Hunt D P, Friedland GH. Pilot study to enhance HIV care using needle exchange-based health services for out of treatment injecting drug users. Yale University AIDS Program, New Haven, Connecticut. J Urban Health 2003; 80: 416-427.

43. Shannon K, Rusch M, Shoveller J, Alexson D, Gibson K, Tyndall MW. Mapping violence and policing as an environmental-structural barrier to health service and syringe availability among substance-using women in street-level sex work. Int J Drug Policy. 2008;19(2):140-7.

44. Subata E, Kriksciukaityte R. Harm reduction programs in Vilnius, the capital of Lithuania. In: LITINTERP, editor. HIV/AIDS prevention amongst injecting drug users in Lithuania: best practices. Vilnius, Lithuania: Central and Eastern European Harm Reduction Network; 2003.

45. Bozinoff N, Wood E, Dong H, Richardson L, Kerr T, DeBeck K. Syringe sharing among a prospective cohort of street-involved youth: implications for needle distribution programs. AIDS Behav. 2017;21(9):1-9.

46. Noroozi M, Mirzazadeh A, Hajebi A, Farhoudian A, Sharifi H, Higgs P, Norooz M. Comparing profile of people who inject drugs (PWID) accessing different types of needle and syringe programs or secondary distribution in Kermanshah, Iran. J Subst Use. 2017;22(3):304-9.

47. Fisher K, Smith T, Nairn K, Anderson D. Rural people who inject drugs: a cross-sectional survey addressing the dimensions of access to secondary needle and syringe program outlets. Aust J Rural Health. 2017;25 (2):94-101.

48. Fernandes RM, Cary M, Duarte $G$, et al. Effectiveness of needle and syringe programmes in people who inject drugs - an overview of systematic reviews. BMC Public Health. 2017:17:309.

49. Chandler R. Best practices for British Columbia's harm reduction supply distribution program: BC Harm Reduction Strategies and Services Committee; 2008.

50. Allen S, Ruiz M, O'Rourke A. How far will they go? Assessing the travel distance of current and former drug users to access harm reduction services. Harm Reduct J. 2015;12:3.

51. Miller M, Eskild A, Mella I, Moi H, Magnus P. Gender differences in syringe exchange program use in Oslo, Norway. Addiction. 2001;96:1639-51.

52. Schechter M, Currie S, Strathdee SA, O'Shaughnessy MV, Patrick DM, Rekart ML, Turvey J, Schechver MT. Maximizing needle exchange coverage among injection drug users (IDUs): do mobile programs attract those at highest risk? Geneva: UNAIDS; 1998.

53. Knittel AK, Wren PA, Gore L. Lessons learned from a peri-urban needle exchange. Harm Reduct J. 2010;7:8.

54. Schwartz RH. Syringe and needle exchange programs: part I. South Med J. 1993;86(3):318-22.

55. Fischer B. Drugs, communities and harm reduction in Germany: the new relevance of public health principles in local responses. J Public Health Policy. 1995;16:389-411.

56. Lausevic D, Begic S, Mugosa B, Terzic N, Vratnica Z, Labovic I, Bozicevic I. Prevalence of HIV and other infections and correlates of needle and syringe sharing among people who inject drugs in Podgorica, Montenegro: a respondent-driven sampling survey. Harm Reduct J. 2015;12:11.

57. Kelsall J, Higgs P, Hocking J, Aitken C \& Crofts N, The Vietnamese harm reduction project: stage 2. The Centre for Harm Reduction, Macfarlane Burnet Centre for medical research, 2001.

58. Strathdee SA, Ricketts EP, Huettner S, Cornelius L, Bishai D, Havens JR, et al. Facilitating entry into drug treatment among injection drug users referred from a needle exchange program: results from a community-based behavioral intervention trial. Drug \& Alcohol Depend. 2006;83(3):225-32.

59. Sharma M, Burrows D, Bluthenthal R. Coverage of HIV prevention for injection drug users: confusions, aspirations, definitions and ways forward. Int J Drug Policy. 2007;18:92-8.

\section{Submit your next manuscript to BioMed Central and we will help you at every step:}

- We accept pre-submission inquiries

- Our selector tool helps you to find the most relevant journal

- We provide round the clock customer support

- Convenient online submission

- Thorough peer review

- Inclusion in PubMed and all major indexing services

- Maximum visibility for your research

Submit your manuscript at www.biomedcentral.com/submit
Biomed Central 